Bibliography and

Research Manual

of the History of

Mathematics 
This page intentionally left blank 
Kenneth O. May

\title{
Bibliography and Research Manual of the History of Mathematics
}

\author{
University \\ of Toronto \\ Press
}




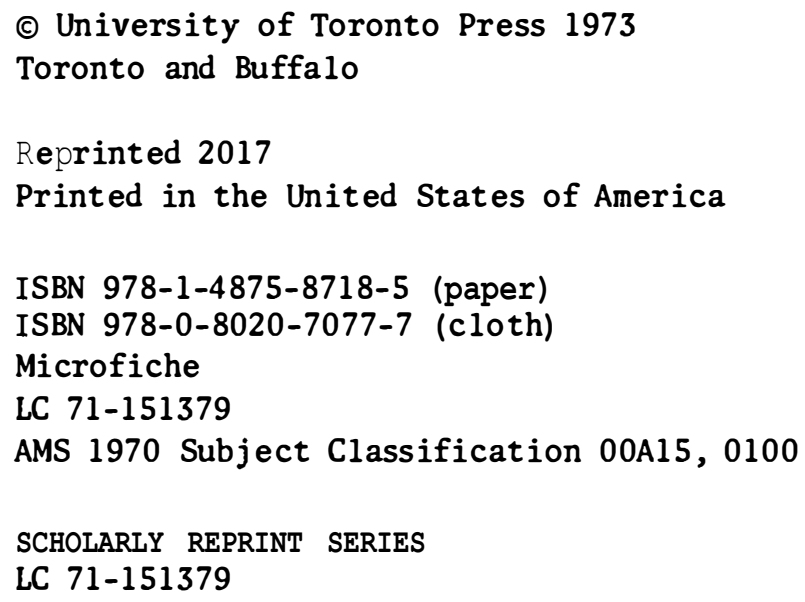

